\title{
Outcome of pregnancy in women with previous one cesarean section
}

\author{
Manish Mittal, Meenakshi Kandoria*, Rajeev Sood, Monica Chauhan, \\ Rohini Rao, Shaina
}

Department of Obstetrics and Gynecology, KNSHM and C, IGMC, Shimla, Himachal Pradesh, India

Received: 31 May 2018

Accepted: 28 June 2018

\section{*Correspondence:}

Dr. Meenakshi Kandoria,

E-mail: mekandoria@gmail.com

Copyright: (C) the author(s), publisher and licensee Medip Academy. This is an open-access article distributed under the terms of the Creative Commons Attribution Non-Commercial License, which permits unrestricted non-commercial use, distribution, and reproduction in any medium, provided the original work is properly cited.

\section{ABSTRACT}

Background: Worldwide rise in cesarean section (CS) rate during the last three decades has been the cause of alarm and needs an in-depth study. The purpose of this study was to determine the outcome of pregnancy in women with previous one cesarean section and maternal and perinatal complications. It also aimed at identifying the factors, which can influence the outcome of trial of labour (TOL).

Methods: The prospective study was conducted in the department of Obstetrics and Gynaecology, Kamla Nehru hospital for mother and child, Indira Gandhi Medical College, Shimla, from June 2013 to May 2014 which included all women undergoing trial for vaginal birth after a previous cesarean who were more than 34 weeks, singleton viable fetus of appropriate size with cephalic presentation with inter delivery interval more than 18 months. Collected data was analysed by Student T-test and Chi-square test was used where required, for statistical analysis using Epi info 7 software. $\mathrm{P}$ value $<0.05$ was considered significant.

Results: Out of 152 subjects given trial of labour, 107 (70.39\%) subjects had successful VBAC and $45(29.61 \%)$ had repeat emergency cesarean section. The maternal morbidity in emergency cesarean section group and vaginal delivered group was seen in $14(31 \%), 8(7.47 \%)$ subjects respectively. No significant perinatal morbidity was observed. VBAC rate was significantly more in women who had prior vaginal deliveries, especially in those with previous VBAC.

Conclusions: In carefully selected cases, trial of labour (TOL) after a prior cesarean is safe and often successful. A prior vaginal delivery, particularly, a prior VBAC are associated with a higher rate of successful TOL.

Keywords: Elective repeat cesarean section, Trial of scar, Trial of labour, VBAC

\section{INTRODUCTION}

Worldwide rise in cesarean section (CS) rate during the last three decades has been the cause of alarm and needs an in depth study. ${ }^{1}$ Before 1970 , deliveries by CS were considered as indication for CS in subsequent pregnancies, reflecting a concern that uterine scar tissue might rupture during labour. ${ }^{2}$ In 1980, the NIH held a Consensus Conference on Cesarean Childbirth in response to concern about a three-fold increase in cesarean deliveries (5\%-15\%) that occurred between
1970 and $1980 .^{3}$ The conference proceedings concluded that women who had a previous cesarean delivery could safely have a subsequent TOL and VBAC, which would lower the overall cesarean delivery rate. VBAC became a popular choice and as predicted, was effective in lowering the cesarean delivery rate. Between 1990 and 1996, the VBAC rate rose from $19.9 \%$ to $28.3 \%$ and the cesarean delivery rate dropped from $22.7 \%$ to $20.7 \% 3$ thus 'once a caesarean always caesarean', espoused by Craigin in 1916, was revised in many countries and vaginal birth after cesarean section grew in popularity. ${ }^{2}$ 
The pendulum began to swing away from routine cesarean section.

A trial of vaginal birth after a previous CS (VBAC) is now considered safer than a routine repeat CS. VBAC offers distinct advantages over a repeat CS since the operative risks are completely eliminated, the hospital stay is much shorter, and expenses involved are much less. The main aims of our study were to determine the outcome of pregnancy in women with prior cesarean section in relation to vaginal delivery, maternal and perinatal complications, and to identify the factors, which can influence the outcome.

\section{METHODS}

The prospective study was conducted in the department of Obstetrics and Gynaecology, Kamla Nehru hospital for mother and child, Indira Gandhi Medical College, Shimla, from $1^{\text {st }}$ June 2013 to $31^{\text {st }}$ May 2014.

\section{Inclusion criteria}

- All women undergoing trial for vaginal birth after a previous cesarean

- More than 34 weeks

- Singleton viable fetus of appropriate size with cephalic presentation with inter delivery interval more than 18 months.

Detail history, clinical and obstetric examination as per hospital protocol had been done with special reference to previous vaginal deliveries, indication for previous caesarean section. All Subjects were admitted near their due date or earlier (if they went into spontaneous labor before expected date). Those who did not go into spontaneous labour after completion of 41 weeks were induced with Foleys Catheter, Progress of labor was recorded on a 'WHO' partogram. Attempt at vaginal delivery was abandoned if there was any suspicion of scar dehiscence or sign of fetal distress or unsatisfactory progress of labour and repeat cesarean section was undertaken. The outcome of vaginal birth after a previous cesarean section, maternal and neonate's details were recorded after delivery till the time of discharge from the hospital.

\section{Statistical analysis}

Student T-test and Chi-square test was used where required, for statistical analysis using Epi info 7 software. $P$ value $<0.05$ was considered significant.

\section{RESULTS}

Out of 152 subjects given trial of labour, 107 (70.39\%) subjects had successful VBAC and 45 (29.61\%) had repeat emergency cesarean section, 90 (59.2\%) subjects went in spontaneous labour and $62(40.8 \%)$ subjects were induced with Foley's catheter.

Out of 90 subjects who went in spontaneous labour, 73 $(81.1 \%)$ subjects had successful VBAC and 17 (18.9\%) subjects had repeat emergency cesarean section (P-value 0.0005 statistically highly significant). Out of 62 subjects who were induced 34 (54.8\%) subjects had successful VBAC and $28(45.2 \%)$ had repeat emergency cesarean section (P-value 0.0005 statistically highly significant).

Table 1: Method of induction and outcome of labour after a previous $\operatorname{LSCS}(\mathbf{n}=152)$.

\begin{tabular}{|c|c|c|c|c|c|c|c|}
\hline Method & $\begin{array}{l}\text { Total No. of } \\
\text { cases }(n=152)\end{array}$ & Percent & $\begin{array}{l}\text { Vaginal delivery } \\
(\mathrm{n}=107)\end{array}$ & Percent & $\begin{array}{l}\text { EMLSCS } \\
(n=45)\end{array}$ & Percent & P-value \\
\hline Spontaneous & 90 & 59.2 & 73 & 81.1 & 17 & 18.9 & $0.0005 * *$ \\
\hline $\begin{array}{l}\text { Induced } \\
\text { (Foleys catheter } \\
\text { +ARM+ Oxytocin) }\end{array}$ & 62 & $40.8 \%$ & 34 & 54.8 & 28 & 45.2 & $0.0005 * *$ \\
\hline
\end{tabular}

Table 2: Method of induction and outcome of labour after a previous LSCS ( $=152)$.

\begin{tabular}{|c|c|c|c|c|c|}
\hline $\begin{array}{l}\text { Indications of emergency } \\
\text { repeat CS }\end{array}$ & $\begin{array}{l}\text { Spontaneous labour } \\
(\mathrm{n}=17 / 90)\end{array}$ & $\begin{array}{l}\text { Percent } \\
(18.8 \%)\end{array}$ & $\begin{array}{l}\text { Induced labour } \\
(n=28 / 62)\end{array}$ & $\begin{array}{l}\text { Percent } \\
(45.2 \%)\end{array}$ & P-value \\
\hline DTA & 1 & 1.1 & 1 & 1.61 & 0.64 \\
\hline Fetal distress & 10 & 11.1 & 13 & 20.96 & 0.15 \\
\hline Non-progress of labour & 3 & 3.3 & 10 & 16.13 & $0.0055 * *$ \\
\hline Scar dehiscence & 0 & 0 & 1 & 1.61 & 0.85 \\
\hline Impending scar rupture & 3 & 3.3 & 3 & 4.84 & 0.64 \\
\hline
\end{tabular}


Table 3: Effect of previous vaginal delivery on TOL after a previous LSCS.

\begin{tabular}{|c|c|c|c|c|c|}
\hline \multirow{2}{*}{$\begin{array}{l}\text { Previous } \\
\text { vaginal } \\
\text { delivery }\end{array}$} & \multicolumn{2}{|c|}{$\begin{array}{l}\text { EMLSCS } \\
(n=45)\end{array}$} & \multicolumn{2}{|c|}{$\begin{array}{l}\text { Vaginal } \\
\text { Delivery } \\
(\mathrm{n}=107)\end{array}$} & \multirow[t]{2}{*}{ P-value } \\
\hline & $\mathbf{N}$ & $\%$ & $\mathbf{N}$ & $\%$ & \\
\hline $\begin{array}{l}\text { Absent } \\
(130 / 152)\end{array}$ & 44 & $33.8 \%$ & 86 & $66.2 \%$ & \multirow{2}{*}{$0.004 * *$} \\
\hline $\begin{array}{l}\text { Present } \\
(22 / 152)\end{array}$ & 1 & $4.55 \%$ & 21 & $95.54 \%$ & \\
\hline
\end{tabular}

**Statistically highly significant

The most common indication of repeat cesarean section was Fetal distress, NPOL, and impending scar rupture.
Fetal distress was in $10(11.1 \%)$ subjects and 13 $(20.96 \%)$ subjects in spontaneous and induced group respectively ( $\mathrm{p}$-value statistically not significant). NPOL was in $3(3.3 \%)$ subjects and $10(16.13 \%)$ in spontaneous and induced group respectively (P-value 0.0055 statistically highly significant). 22 subjects who belonged to parity $>2$ group, $21(95.45 \%)$ subjects had successful vaginal delivery after TOL and1(4.55\%) subject had EMLSCS.

The mean birth weight was $2.73 \pm 0.43 \mathrm{~kg}$ in vaginal delivery group and $2.81 \pm 0.38 \mathrm{~kg}$ in emergency cesarean section. This was statistically not significant (P-value 0.23 .

Table 4: Bishop score and mode of delivery after a previous LSCS.

\begin{tabular}{|c|c|c|c|c|c|c|c|}
\hline Bishop score & $\begin{array}{l}\text { Total no. cases } \\
(n=152)\end{array}$ & Percent & $\begin{array}{l}\text { Vaginal delivery } \\
(\mathrm{n}=107)\end{array}$ & Percent & $\begin{array}{l}\text { EMLSCS } \\
(n=45)\end{array}$ & $\%$ & P-value \\
\hline $0-2$ & 6 & 3.95 & 0 & 0 & 6 & $100 \%$ & $0.0001 * *$ \\
\hline $3-5$ & 56 & 36.84 & 34 & 60.7 & 22 & $39.3 \%$ & $0.045^{*}$ \\
\hline$\geq 6$ & 90 & 59.21 & 73 & 81.1 & 17 & $18.9 \%$ & $0.00048 * *$ \\
\hline
\end{tabular}

**Statistically significant $*$ Statistically significant

Table 5: Indication for previous LSCS and present pregnancy outcome after TOL.

\begin{tabular}{|lllllll|}
\hline $\begin{array}{l}\text { Indication of previous cesarean } \\
\text { section }\end{array}$ & $\begin{array}{l}\text { Total no of } \\
\text { cases }\end{array}$ & $\begin{array}{l}\text { Vaginal } \\
\text { delivery }\end{array}$ & Percent & EMLSCS & Percent & P-value \\
\hline Malpresentation & 46 & 39 & 84.78 & 7 & 15.22 & $0.01 *$ \\
\hline CPD & 13 & 3 & 23.08 & 10 & 76.92 & $0.0001 * *$ \\
\hline fetal distress & 62 & 51 & 82.26 & 11 & 17.74 & $0.01 *$ \\
\hline NPOL & 14 & 5 & 35.71 & 9 & 64.29 & $0.002 * *$ \\
\hline placenta previa & 7 & 4 & 57.1 & 3 & 42.9 & 0.43 \\
\hline Preeclampsia & 3 & 3 & 100 & 0 & 0 & 0.55 \\
\hline Twins & 3 & 2 & 66.6 & 1 & 33.4 & 1.0 \\
\hline failed induction & 4 & 0 & 0 & 4 & 100 & $0.0069 * *$ \\
\hline
\end{tabular}

**Statistically significant $*$ Statistically significant

Out of 22 subjects with a previous vaginal delivery $21(95.84 \%)$ subjects had successful VBAC as compared to 130 subjects with no history of previous vaginal delivery in whom successful trial of labour was in 86 $(66.2 \%)$ subjects (P-value 0.004 statistically highly significant). Subjects with parity 2 and more, 21 $(95.45 \%)$ subjects delivered vaginally and 1 (4.55\%) subject, delivered by cesarean section.

This difference was statistically highly significant (Pvalue 0.0044). This was observed that as the parity increases, there is decrease in cesarean section after trial of labour in subjects with a previous cesarean section.

There were $6(3.95 \%)$ subjects with bishop score $0-2$ out of 152 subjects whom trial of labour was given all of them had repeat emergency cesarean section. There were $56(36.84 \%)$ subjects with bishop score 3-5 out of which
$34(60.7 \%)$ subjects had successful vaginal delivery and $22(39.3 \%)$ had repeat emergency cesarean section. There were $90(59.21 \%)$ subjects with bishop score $>6$ out of which $73(81.1 \%)$ subjects had successful vaginal delivery and $17(18.8 \%)$ had repeat emergency cesarean section. It is observed that with increase in bishop score, rate of successful trial of labour increases.

There was significantly high percentage of successful VBAC in subjects whose primary cesarean was done for Non-recurrent indication i.e. Mal-presentation 46 subjects and fetal distress 62 subjects with successful VBAC in 39 $(84.78 \%)$ and $51(82.26 \%)$ subjects respectively. The percentage of successful VBAC was significantly less in subjects where primary cesarean section was done for recurrent indication in 13 subjects with mild CPD and 14 subjects with NPOL with successful VBAC in 3 subjects $(23.08 \%)$ and $5(35.71 \%)$ subjects respectively. 
The maternal morbidity in emergency cesarean section group and vaginal delivered group was seen in $14(31 \%)$, and $8(7.47 \%)$ respectively. The neonatal morbidity was seen in $8(17.8 \%)$ neonates delivered vaginally, 16 $(14.95 \%)$ neonates delivered by repeat emergency cesarean section.

Admission of neonates in neonatal intensive care unit, when compared between vaginally delivered group and repeat emergency cesarean section group was $10(9.3 \%)$ and $8(17.8 \%)$ neonates respectively. There was $1(2.2 \%)$ neonatal deaths in emergency repeat cesarean section subjects and $4(3.74 \%)$ neonatal deaths in vaginally delivered subjects. $1(0.93 \%)$ neonate who delivered vaginally was still born and no neonate was still born in subjects who had EMLSCS (P-value 0.31 statistically not significant).

Table 6: Admission in neonatal intensive care unit depending on outcome of TOL.

\begin{tabular}{|c|c|c|c|c|}
\hline \multicolumn{2}{|c|}{ EMLSCS $(n=45)$} & \multicolumn{2}{|c|}{$\begin{array}{l}\text { Vaginal delivery } \\
(\mathrm{n}=107)\end{array}$} & \multirow{2}{*}{$\begin{array}{l}\text { P- } \\
\text { value }\end{array}$} \\
\hline $\begin{array}{l}\text { Number of } \\
\text { cases }\end{array}$ & $\%$ & $\begin{array}{l}\text { Number of } \\
\text { case }\end{array}$ & $\%$ & \\
\hline 8 & $17.8 \%$ & 10 & $9.3 \%$ & 0.14 \\
\hline
\end{tabular}

The mean duration of hospital stays after successful VBAC and repeat emergency cesarean section after trial of labour was $2.73 \pm 2.21$ and $4.51 \pm 1.83$ days respectively (P-value 0.000 highly significant).

\section{DISCUSSION}

Vaginal birth after cesarean (VBAC) been an important tool in an attempt to decrease the increasing cesarean rate. This has been possible especially because of improvement in the type of uterine incision, better antibiotic, continuous maternal and fetal monitoring during labour. So, the present study was undertaken to evaluate the predictive factors for successful vaginal birth after previous one cesarean section

In the present study, $72.97 \%$ of booked subjects had successful trial of labour and $27.03 \%$ had repeat cesarean section which was comparable to study conducted by Wazzan et al. $^{4}$ In the present study $66.15 \%$ of para-1, $95.45 \%$ of subjects with parity 2 or more, subjects had successful trial of labour, which was comparable to study conducted by Wazzan et al and Gonen $\mathrm{R}$ et al. ${ }^{4,5}$ It was concluded from the study that with increase in parity the rate of success of trial of labour increases.

Mean birth weight for successful trial of labour was $2730 \pm 430$ grams and mean birth weight was $2810 \pm 380$ grams for repeat caesarean section which was comparable to studies conducted by Madaan $\mathrm{M}$ et al and Eskander $\mathrm{M}$ et al. ${ }^{6,7}$ It was observed that the fetal birth weight had no effect on mode of delivery in trial of labour. Bishop score of $0-2,3-5,>6$ had successful vaginal delivery $0 \%$,
$60.7 \%, 81.1 \%$ respectively which was comparable to study done by Bujold $\mathrm{E}$ et al. ${ }^{8}$ The Bishop Score improves the success of vaginal delivery also increases after trial of labour in previous cesarean section subjects. Weinstein D et al (1996), it was observed that Bishop Score $>4$ in the current pregnancy was the strongest and most significant predictor for successful vaginal birth after cesarean section. ${ }^{9}$

Subjects with history of previous vaginal delivery had 95.84\% successful trial of labour comparable to studies conducted by Hendler I et al, Al-Wazzan RM et al and Chaudari DR et al. ${ }^{40}$ It is concluded that the trial of labour with history of previous vaginal delivery had more chances of successful VBAC.

It is observed that successful vaginal delivery rate was $82.26 \%$ in subjects who had fetal distress , $84.78 \%$ in subjects who had mal presentation, $23.08 \%$ in subjects who had CPD as indication for previous cesarean section which was comparable to studies by Puri $\mathrm{P}$ et al, Chaudhari DR et al and Balachendren L et al. ${ }^{10-12}$ It was seen that non recurrence indications like fetal distress, mal-presentation had high successful vaginal delivery rate than recurrent indication like CPD and NPOL after trial of labour in subjects with a previous lower segment cesarean section.

In present study $59.21 \%$ subjects had unassisted vaginal delivery, $9.87 \%$ subjects had forceps delivery, $1.32 \%$ subjects had ventouse delivery which was comparable to study done by Chaudhari DR et al. ${ }^{10}$ The higher rate of forceps and ventouse delivery as observed in the studies by Vardhan S et al, Puri P et al and Rahman R et al was because they had applied prophylactic forceps and ventouse more frequently to cut short $2^{\text {nd }}$ stage of labour. ${ }^{11,13,14}$

In present study indication of repeat emergency cesarean section was fetal distress in $51.1 \%$ NPOL in $28.9 \%$, impending scar rupture was in $15.6 \%$ of subjects which was comparable to study conducted by Mafatlal SJ et al and Taj A et al. ${ }^{1,15}$

In present study $1.87 \%$ and $13.3 \%$ suffered from urinary tract infections in vaginal delivery group and the subjects who had emergency cesarean section respectively. This was comparable to study done by Chaudhari DR et al. ${ }^{11}$ In present study $0.93 \%$ suffered from pyrexia in vaginal delivery group comparable to study done by Rahman $\mathrm{R}$ et al. ${ }^{14}$

Infected wound was observed in $2.12 \%$ and $0.93 \%$ in study conducted by Chaudhari DR et al and present study respectively, in vaginally delivered group. ${ }^{11}$ Infected wound was $0.6 \%, 8.23 \%, 0.48 \%, 3.77 \%, 8.23 \%$ and $8.9 \%$ respectively by Blanchette $\mathrm{H}$ et al, Landon $\mathrm{M} B$ et al, Puri P et al, Chaudhari. DR et al, Rahman $\mathrm{R}$ et al and present study in emergency cesarean section group respectively..$^{10,11,14,16,17}$ 
It is concluded that maternal morbidity was more in emergency cesarean section group as compare to vaginal delivery group after trial of labour in subjects with previous one lower segment cesarean section. In present study $6.53 \%$ neonates of subjects who had successful vaginal delivery, $15.7 \%$ neonates of subjects who had repeat emergency after trial of labour had Apgar score of $<7$ at 1 minute which was comparable to study conducted by Blanchette $\mathrm{H}$ et al. ${ }^{16}$

It is observed that neonates delivered vaginally with Apgar score $<7$ at 1 minute did not improve after 5 minutes in present study. In present study admission in intensive care unit in neonate's delivery vaginally was $9.3 \%$, in $17.8 \%$ delivered by repeat emergency cesarean section which was comparable with study conducted by Blanchette $\mathrm{H}$ et al and Eskandar $\mathrm{M}$ et al. ${ }^{7,16}$

In present study $3.74 \%$ neonatal death had occurred in subjects after success trial of labour $2.2 \%$ neonatal death had occurred in subjects delivered by repeat emergency cesarean section with a previous cesarean section.

The result was comparable with studies conducted by Agarwal A et al and Chaudhari DR et al. ${ }^{10,18}$ It is thus concluded that neonatal mortality is more in subjects who had successful vaginal delivery after trial of labour.

Average hospital stay was 2.73 days, repeat emergency cesarean section, average hospital stay was 4.51 days which was comparable to studies conducted by Hibbard $\mathrm{JU}$ et al and Bangal BV et al. ${ }^{19,20}$ It is concluded that average stay in subjects who had repeat cesarean section was more than subjects who had successful vaginal delivery after a previous lower segment cesarean section.

\section{CONCLUSION}

From the present study it is concluded that there are many factors in the history and examination of the subjects who had pregnancy with previous cesarean section which can be identified, on the basis of these factors the subjects can be given trial of labour. Obstetrics' risk factors like history of previous vaginal delivery, Bishop Score, estimated fetal birth weight, spontaneous or induced labour have great bearing on the success of TOL.

By proper identification of these factors the success rate and safe vaginal delivery can be determined in subjects given trial of labour after a previous cesarean section and thus VBAC as an integral part of good obstetric care. Women should be allowed to make an informed choice and more information regarding safety and prediction for success should be preserved.

\section{Funding: No funding sources} Conflict of interest: None declared

Ethical approval: The study was approved by the Institutional Ethics Committee

\section{REFERENCES}

1. Mafatlal SJ, Narendrabhai MM. Analysis of mode of delivery in women with one cesarean section. JObstet Gynecol India. 2009;59(2):136-39.

2. Gupta P, Jahan I, Jograjiya GR. Is vaginal delivery safe after previous lower segment caesarean section in developing country? Niger Med J. 2014;55:260-5.

3. King TL. First do no harm: the case for vaginal birth after cesarean. J Am college of Nurse-midwives. 2010;55(3):202-5.

4. Wazzan-Al. RM. Factors affecting success of trial of labour after previous one lower segment Caesarean section. J Ann. Coll. Med. Mosul. 2010;36(1\&2):121-9.

5. Gonen R, Barak S, Tamir A, Ohel G. Results of a well-defined protocol for a trial of labor after prior caesarean section.J Obstet Gynecol. 2006;107:240-5.

6. Madaan M, Agrawal S, Nigam A, Aggarwal R, Trivedi SS.Trial of labour after previous caesarean section: the predictive factors affecting outcome. J Obstet Gynecol. 2011;31(3): 224-8.

7. Eskander M, Jameelah A, Majed A, Mervat H, Azza. Optimization of clinical outcome of women with previous one lower segment cesarean section. J Obstet Gynecol. 2012;2:265-9.

8. . Bujold E, Blackwell CS, Hendler I, Berman S, Sorokin Y, Gauthier JR. Modified Bishop's score and induction of labor in patients with a previous cesarean delivery.Am J Obstet and Gynecol 2004; 19:1644-48.

9. Weinstein D, Benshushan A, Ezra Y, Rojansky N. Vaginal birth after cesarean section. Int J Gynaecol Obstet. 1996; 53:1-10.

10. Chaudhari DR, Shinde SM. Clinical profile and outcome of labour in cases following previous caesarean section. Int $\mathrm{J}$ Observational study. Int $\mathrm{J}$ of Women's Health. 2012:6 301-5.

11. Puri P, Abraham M, Grover S. Vaginal birth after one previous lower segment caesarean section. J K Sci. 2011; 13(4).180-1.

12. Balachandran L, Vaswani RP and Mogotlane R. Pregnancy outcome in women with previous one cesarean section. J Clin Diag Res. 2014;8(2):99-102.

13. Vardhan S, Behera RC, Sandhu GS, Singh A, Bandhu HC. Vaginal birth after caesarean delivery. J Obstet Gynecol India. 2006; 56(4): 320-3.

14. Rahman R, Khanam NN, Islam N, Begum KF, Pervin HH, Arifuzzaman M. The outcome of vaginal birth after caesarean section (VBAC): a descriptive study. Medicine Today. 2013;25(1):14-7.

15. Taj A, Naqvi SB, Yasmeen T. Vaginal birth after caesarean section at Liaquat National Hospital. Pak J Surg. 2012;28(1):81-4.

16. Blanchette H, Blanchette M, McCabe J, Vincent S. Is vaginal birth after cesarean safe? Experience at a community hospital. Am J Obstet Gynecol. 2001;184:1478-84; discussion 1484-87.

17. Landon MB, Leindecker S, Spong C, Hauth JC, Bloom S, Varner MW et al. The MFMU Cesarean 
Registry: Factors affecting the success of trial of labor after previous cesarean delivery. Am J Obstet Gynecol. 2005;193(3):1016-23.

18. Agarwal A, Chowdhary P, Das V, Srivastava A, Pandey A, Sahu MT. Evaluation of pregnant women with scarred uterus in a low resource setting. J Obstet Gynaecol Res. 2007;33(5):651-4.

19. Hibbard. JU, Muhammed IA, Yantao W, Catherine T, Karrison T. Failed vaginal birth after a cesarean section: How risky is it?. Am J Obstet Gynecol. 2001;184:1365-73.
20. Bangal VB, Giri PA, Shinde KK, Gavhane SP. Vaginal birth after cesarean section. North Am J Med Sci. 2013; 5:140-44.

Cite this article as: Mittal M, Kandoria M, Sood R, Chauhan M, Rao R, Shaina. Outcome of pregnancy in women with previous one cesarean section. Int $\mathbf{J}$ Reprod Contracept Obstet Gynecol 2018;7:3257-62. 